\title{
RoPE - Brinquedo de Programar e Plataforma de Aprender
}

\author{
André Luís Alice Raabe ${ }^{1,2,3}$, André Luiz Maciel Santana ${ }^{1}$, Rodrigo Ramos \\ Martins $^{1,3}$, Felipe Teixeira de Souza ${ }^{1}$, Tatiane A. M. do Rosário ${ }^{1,2}$, Raphael da Silva ${ }^{1}$ \\ ${ }^{1}$ Laboratório de Inovação Tecnológica na Educação - CTTMar - UNIVALI \\ ${ }^{2}$ Programa de Pós-Graduação em Educação \\ ${ }^{3}$ Mestrado em Computação Aplicada \\ raabe@univali.br, andrelms@univali.br, lite@univali.br
}

\begin{abstract}
The paper describes the design, improvement and results of using RoPE - Educational Programmable Robot in Early Childhood Education. The RoPE was built to enable children from 4 to 8 years old to have their first contacts with mathematical and algorithmic concepts, but its use by teachers has gone beyond the initial intention to become a learning platform in which children and teachers construct together projects as microworlds to use the toy.

Resumo. $O$ artigo descreve a concepção, aprimoramento e resultados de uso do RoPE - Robô Programável Educacional em escolas de Educação Infantil. O RoPE foi construído para possibilitar crianças de 4 a 8 anos a terem os primeiros contatos com conceitos matemáticos e algorítmicos, mas sua utilização pelos professores tem ultrapassado a intenção inicial tornando-se uma plataforma de aprender, na qual professores e crianças constroem projetos na forma de micromundos para explorar o brinquedo de forma integrada ao planejamento pedagógico do professor.
\end{abstract}

\section{Introdução}

Brinquedos de programar possibilitam que desde a educação Infantil as crianças possam ter contato com conceitos relacionados ao pensamento computacional como algoritmos, reconhecimento de padrões e a resolução de problemas. Normalmente estes brinquedos apresentam-se na forma de um veículo com rodas e assumem aparências diversas como robô, carro, tanque, abelha, e outras figuras representativas do imaginário infantil (RAABE et. al, 2015a).

O presente artigo relata os resultados iniciais do projeto RoPE, que viabiliza a produção, entrega e uso de Brinquedos de Programar por escolas de Educação Infantil do município de Balneário Camboriú no estado de Santa Catarina. O nome RoPE vem de Robô Programável Educacional e trata-se da primeira iniciativa de uso sistemático destes brinquedos por uma rede de ensino pública no Brasil. O projeto RoPE é resultado de mais de 3 anos pesquisas de enfoque interdisciplinar envolvendo aproximadamente 20 
pesquisadores de Educação, Ciência da Computação, Design e Engenharias Mecânica, Computação e Arquitetura. As pesquisas, com enfoques complementares, permitiram o projeto, a prototipação, o teste e aprimoramento do brinquedo, bem como ampliaram o conhecimento sobre o ambiente de sua utilização na escola, a relação das crianças com a interface de programar e sobre boas práticas pedagógicas para sua utilização (RAABE et al., 2015b).

A fase crucial do projeto iniciou quando as escolas passaram a receber os brinquedos e os professores de educação infantil se depararam com a possibilidade (e o desafio) de incluí-los em sua prática pedagógica. Para auxiliar neste processo os pesquisadores realizam a formação dos professores para uso do brinquedo, também sugeriram atividades como forma de inspiração inicial, realizaram dinâmicas motivando a criação de planos de atividades e participaram das primeiras atividades com as crianças.

A estratégia tem se mostrado adequada e permitiu que novas atividades fossem criadas pelos professores, que identificaram formas diferentes de explorar o uso do brinquedo. As novas abordagens permitiram que os pesquisadores perceberem que mais do que um artefato que auxilia a realização de tarefas e que estimulem conceitos matemáticos e a resolução de problemas, o brinquedo de programar está se tornando uma plataforma de aprender. Professores e estudantes tornam-se autores de cenários de aprendizagem contextualizados com os temas sendo trabalhados pelo professor, aproximando-se do conceito de micromundos preconizado por Papert (2008).

O artigo apresenta na seção 2 o brinquedo RoPE e sua interface. A seção 3 apresenta os materiais de apoio e a seção 4 descreve a formação dos professores. A seção 5 detalha os contatos iniciais das crianças e a seção 6 apresenta os cenários criados por professores que configuram a ideia de uma plataforma de aprender. A seção 7 apresenta as considerações finais do trabalho.

\section{O Brinquedo RoPE}

Brinquedos de programar têm sido concebidos e pesquisados especialmente fora do Brasil, como em Highfield \& Hedberg (2008) e Janka (2008). Por vezes associado a robótica como em Kazarof \& Bers (2013). No entanto, a construção de um brinquedo de programar voltado para a realidade social, educacional e econômica brasileira precisa conhecer e considerar estas especificidades.

Neste espírito, os pesquisadores que construíram o RoPE priorizaram decisões que pudessem reduzir o custo e tornar o brinquedo aderente a realidade dos núcleos de educação infantil brasileiros. Toda a produção do brinquedo ocorre de forma artesanal e é realizada com a infraestrutura do Laboratório de Inovação Tecnológica na Educação (LITE) da Univali, utilizando recursos como prototipação digital, criação de placas controladoras e desenvolvimento de firmwares para o hardware especificado. Além disso, foram realizadas várias interações com escolas da rede pública de ensino com o objetivo de promover a participação dos estudantes e educadores nas etapas de projeto do brinquedo. Estes resultados são relatados em (MARTINS, 2016; PINHEIRO, 2016; RICHTER et al, 2016 e SANTANA, 2015)

Para programar o RoPE usa-se 5 botões coloridos ilustrados na figura 1 à 
esquerda. Quatro botões servem para inserir as instruções de direção para o brinquedo que são: (i) avançar um passo (ii) retroceder um passo (iii) girar 90 graus à direita (iv) girar 90 graus à esquerda. Em um passo o RoPE se desloca por exatamente 15 centímetros. O botão do centro inicia a execução do programa inserido pela criança por meio dos botões de direção. A Figura 1 à direita apresenta a aparência do RoPE.

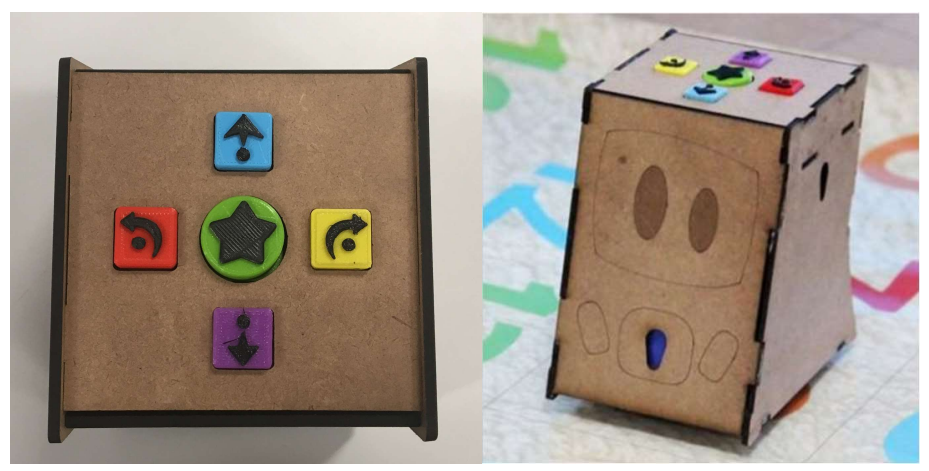

Figura 1. Interface de Programação e Aparência do RoPE

Quatro formas diferentes de representar a direção do movimento foram definidas para auxiliar as crianças. A primeira é a forma do movimento em alto relevo nos botões. A segunda por meio das cores dos botões, que foram sugestões apresentadas pelos educadores durante as etapas de criação do brinquedo. A terceira por meio de representações sonoras emitindo um som para cada direção permitindo a associação entre cor-movimento-som. E a quarta, por meio de luzes laterais que seguem as mesmas cores dos botões de movimentação. No uso do brinquedo as crianças programam e executam os comandos, que podem ser inseridos todos de uma única vez ou divididos em partes menores. Após o término de um programa o brinquedo emite um som caracterizando o fim da execução.

Com os primeiros protótipos funcionais foi possível realizar um primeiro teste piloto junto a 9 crianças com idade entre 3 e 4 anos de uma creche pública do município de Itajaí (SC). Este teste também auxiliou a validação da metodologia de uso proposta por Martins (2016), que tem por objetivo trabalhar habilidades de engenharia com o uso do brinquedo. Durante o piloto foi possível perceber a necessidade de aprimoramentos no brinquedo para se adequar as salas usadas na educação infantil que tinham o piso irregular criando obstáculos para movimentação do brinquedo. $O$ teste e a experiência das professoras auxiliaram a definição de aspectos como o tempo de duração das atividades, a relação de quantidade de crianças por brinquedo, que tipos de atividades tem maior potencial e também como auxiliar os professores no planejamento destas.

\section{Os Materiais de apoio}

Junto com o brinquedo foram confeccionados materiais de apoio ao trabalho do professor, sendo eles o Guia do Professor e os tapetes pedagógicos. No Guia do professor é feita uma apresentação do brinquedo e suas funcionalidades bem como são sugeridos três planos de aula que detalham objetivos, duração, estratégias, procedimentos e adaptações possíveis. As atividades sugeridas tiveram por objetivo auxiliar as professoras nos primeiros passos para inserir o brinquedo nas aplicações em sala de aula. Os planos foram 
construídos com o suporte de uma pesquisa de Mestrado em Educação, base que desenvolveu metodologias para uso de brinquedos de programar em consonância com as Orientações Curriculares Municipais do município. Os planos foram construídos de modo a introduzir gradativamente o brinquedo e o conceito de programação junto às crianças.

Já os tapetes pedagógicos (Figura 2) foram elaborados para serem entregues junto com os brinquedos. O tapete é o local onde o brinquedo executa seus movimentos, servindo como apoio para o desenvolvimento de histórias e desafios para as crianças.
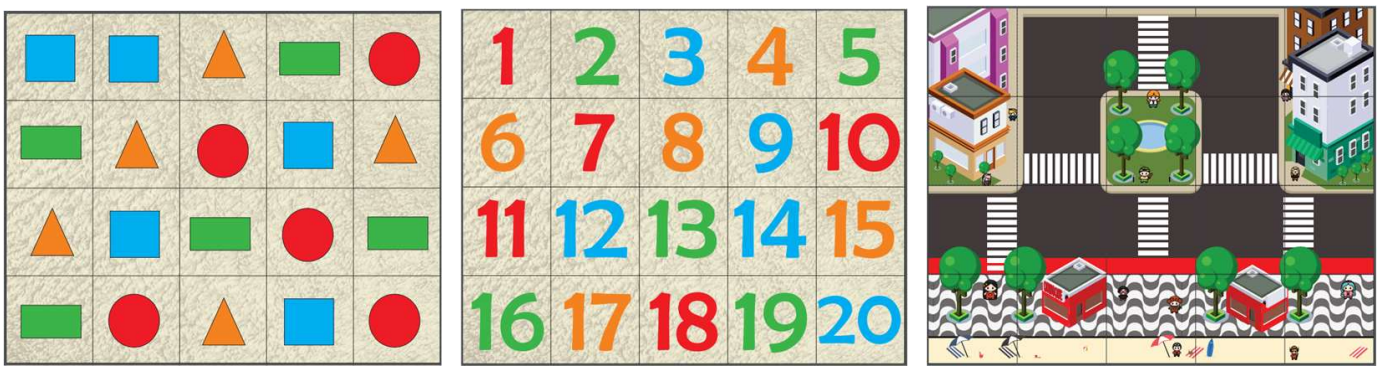

Figura 2. Tapetes pedagógicos entregues com o RoPE

Com os tapetes é possível realizar atividades como o reconhecimento de formas e números, a entrega de correspondência em uma cidade, a simulação de situações no trânsito. Foram construídos tapetes que abordavam os conteúdos trabalhado já no currículo da educação infantil. O tapete é construído tendo como base quadrados de $15 \mathrm{~cm}$, equivalente ao deslocamento de um passo do brinquedo, sendo possível fazer a associação entre a quantidade de passos e de quadrados no tapete.

O guia do professor ainda sugere que os educadores façam novos tapetes usando materiais comuns e que a escola possui, como por exemplo: cola, fita adesiva colorida, papel pardo, cartolina etc.

\section{A Formação dos professores}

O projeto firmado com a Secretaria de Educação de Balneário Camboriú prevê a entrega de 30 brinquedos distribuídos para 10 núcleos da educação infantil (NEI) (três brinquedos por escola), contemplando aproximadamente 1600 crianças. Esta demanda foi escalonada para ser atendida durante o ano de 2017. A primeira remessa contendo três brinquedos foi destinada ao núcleo de educação infantil Carrossel.

O núcleo possui 10 professores responsáveis que atendem ao todo 170 crianças do Jardim I e Jardim II (4 a 6 anos de idade). O primeiro contato dos professores com o RoPE ocorreu em uma parada pedagógica do núcleo, onde os pesquisadores puderam realizar a formação para o uso do brinquedo. A Figura 3 ilustra algumas das interações das professoras com o brinquedo. 


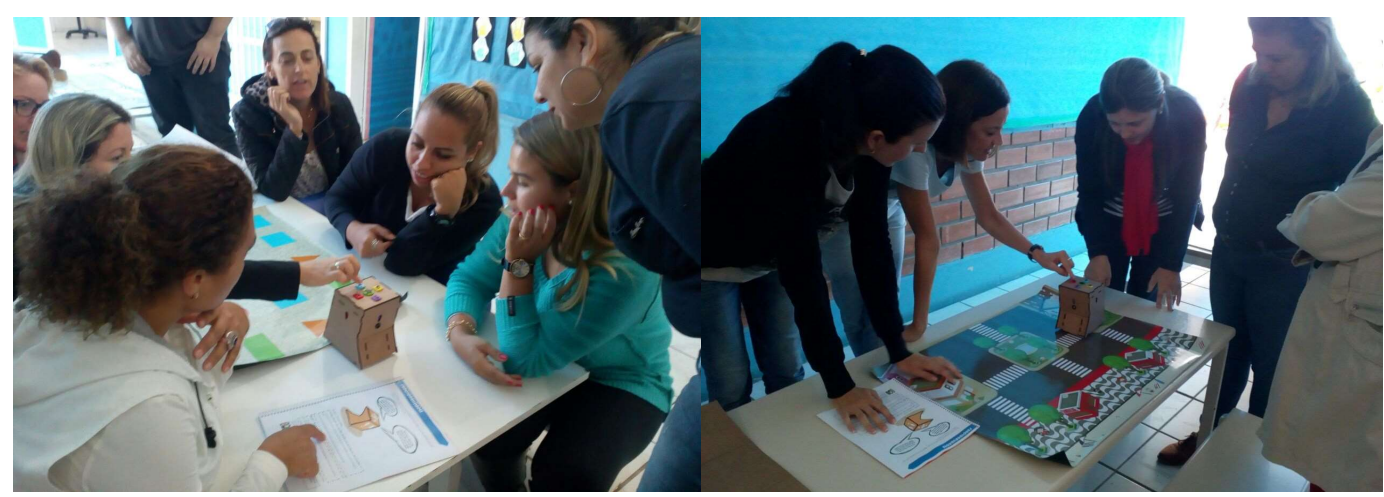

Figura 3. Formação das professoras

A formação apresentou o histórico do projeto e como o brinquedo foi concebido tendo tido a participação de professores de Educação Infantil e pesquisadores de diferentes áreas. Ressaltou-se também o potencial do brinquedo para trabalhar conceitos como estimativas, o conceito de número, lateralidade, trajetórias, rotação, algoritmo e decomposição de problemas.

Os planos de aula sugeridos no Guia do Professor foram executados pelos formadores tendo as professoras, na ocasião, o papel que futuramente seria o das crianças. No decorrer das ações com o brinquedo as professoras brincaram, dialogaram e compreenderam que o brinquedo precisava ser programado para que pudesse se movimentar. A mediação da equipe de formadores foi mínima, as professoras exploraram e criaram trajetos e direções de suas preferências com o brinquedo. Percebeu-se que o entendimento a respeito do funcionamento e cuidados (bateria, tempo de recarga, manuseio) com o RoPE foi rápido, bem como sua aceitação.

Os formadores também enfatizaram a possibilidade dos professores criarem novos tapetes usando materiais da escola. Foi notório o entusiasmo demonstrado pelas professoras e em várias falas elas deram indícios que vislumbravam usos do brinquedo de programar em consonância com seus planejamentos pedagógicos. Outro ponto positivo apontado pelas professoras é de o brinquedo oportunizar às crianças a possibilidade de explorar outros espaços da escola, uma vez que os tapetes e os brinquedos podem ser usados em qualquer local plano.

\section{Contato inicial das Crianças}

$\mathrm{Na}$ semana seguinte à formação das professoras, foi a vez das crianças conhecerem o brinquedo de programar. A coordenadora do núcleo escolheu uma turma de crianças do Jardim II (5 e 6 anos) para conhecer e explorar o brinquedo. Na roda de conversa na sala de aula, o RoPE foi apresentado dentro de uma caixa surpresa, instigando as crianças a falarem o que continha dentro da caixa. Após a apresentação do brinquedo, foi explorado suas características. O RoPE foi passado de mão em mão para que as crianças pudessem manuseá-lo. A equipe de pesquisadores estava presente para orientar as primeiras interações caso fosse necessário.

O primeiro momento foi de descobertas por parte das crianças, acionando os comandos do brinquedo, programando movimentos livres pela sala e conhecendo as funções dos botões. No segundo momento, a professora responsável apresentou para as 
crianças o tapete pedagógico e propôs desafios (figura 4). O clima de cooperação entre as crianças foi estabelecido, as que tinham um pouco mais de dificuldade em entender o funcionamento dos comandos foram auxiliadas por aquelas que compreendiam rapidamente como o brinquedo funcionava.

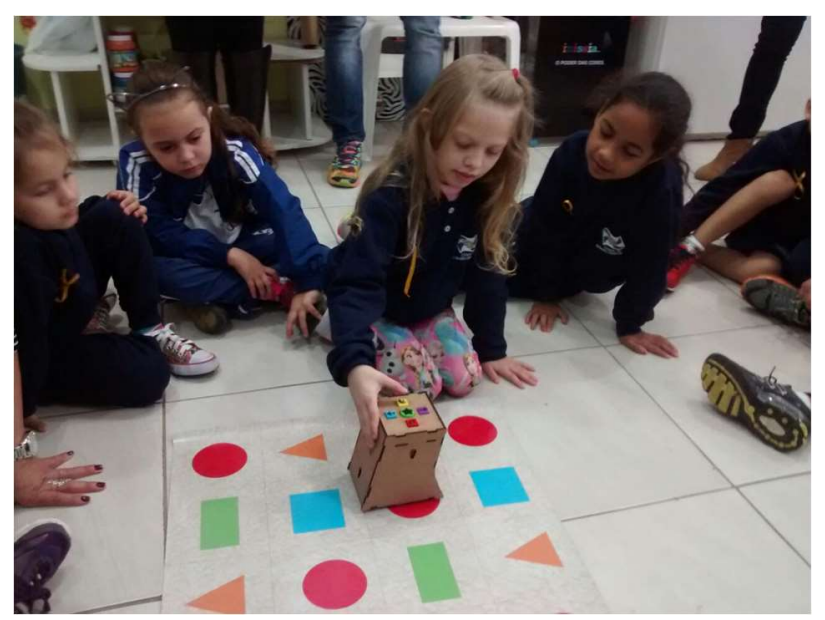

Figura 4. Crianças interagindo com o RoPE

As atividades planejadas para este momento foram pensadas a partir dos conhecimentos prévios das crianças, com o intuito de prepará-las para a execução das atividades. Ao propor essas dinâmicas para as crianças houve o cuidado para que as mesmas as realizassem com autonomia, respeitando o tempo de cada criança.

Observou-se nessa atividade que a maioria das crianças compreenderam o movimento do giro (conceito que tinha gerado dúvidas nas crianças nos testes piloto). As crianças não tiveram dificuldades em acionar os botões para o brinquedo se deslocar. $\mathrm{O}$ brinquedo atraiu a atenção das crianças, sensibilizando as professoras a incluírem em seus planejamentos pedagógicos o uso do brinquedo de programar nas atividades. No decorrer do processo quando da aplicação das atividades, algumas professoras apontaram sugestões de mudança para a melhoria do brinquedo, como por exemplo que o volume do som fosse um pouco mais alto devido ao ruído da sala de aula.

Não está no escopo deste artigo explorar as diferentes aprendizagens que ocorreram quando da utilização pelo brinquedo pelas crianças. Um outro artigo está sendo elaborado com este enfoque. $\mathrm{O}$ interesse está em ilustrar de que forma o brinquedo passou a ser incorporado pelas professoras em suas atividades, o que será descrito a seguir.

\section{Resultados iniciais: Em direção a uma plataforma para aprender}

Após a entrega e os contatos iniciais, o Núcleo de educação infantil passou a operacionalizar o uso do RoPE como material pedagógico da escola. A diretora da escola mantém os brinquedos e os tapetes na sala da coordenação, e os docentes que desejarem solicitam-no para ser utilizado.

Já nas primeiras semanas pelo menos dois professores passaram a usá-lo de forma mais sistemática e já realizaram em torno de 8 atividades de aproximadamente uma hora de duração cada. A maioria das atividades vêm sendo realizadas dividindo as turmas em 
VI Congresso Brasileiro de Informática na Educação (CBIE 2017)

Anais do XXIII Workshop de Informática na Escola (WIE 2017)

três grupos trabalhando cada grupo com um tapete e um RoPE.

Como foi estimulado que o professor também criasse seus próprios tapetes com materiais que os núcleos oferecem. Isto passou a acontecer com pelo menos duas professoras (referidas a seguir como Professora A e B) que passaram a realizar a criação de materiais complementares para o brinquedo. A professora $\mathrm{A}$ já tinha participado dos testes piloto e já possuía mais tempo de uso do brinquedo. A professora B iniciou o uso do RoPE apenas quando o brinquedo chegou à escola. Os pesquisadores solicitaram a elas que registrassem suas criações e os relatos a seguir são destas professoras.

Quanto ao planejamento da atividade a professora A descreveu:

"Criei uma atividade relacionada às rotinas de vivências da educação infantil. No primeiro momento a criança tinha que lançar o dado contendo seis tipos de rotinas. Dai ela tinha que realizar o percurso no tapete com o brinquedo de acordo com a rotina sorteada. Usei papel cartolina branca, fitas adesivas coloridas, imagens impressas relacionadas à rotina diária das crianças e um dado contendo as mesmas imagens que continha no tapete que fiz com papelão e papel colorido. “

(Professora A)

A figura 5 ilustra o material elaborado pela professora A para realização desta atividade.

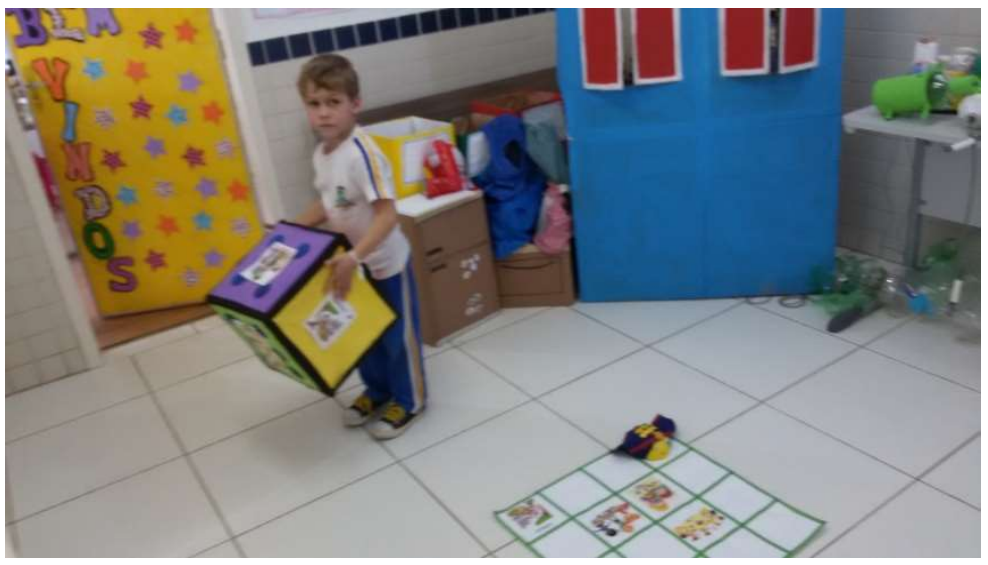

Figura 5 - Materiais elaborados pela professora A

Quanto a realização da atividade a professora relatou:

"Participaram dessa atividade dezoito crianças. A dinâmica aconteceu em grupo em um ambiente fora o da sala de aula. Observamos as imagens contendo seis tipos de rotinas de vivência da educação infantil, representada por figuras no qual conversamos sobre elas. Logo individualmente as crianças lançaram o dado e a figura que ficou virada para cima, sendo esta o ponto final do caminho a ser pelo RoPE no tapete. "(Professora A)

Em um segundo tapete a professora A construiu um cenário associado com a contação de história infantil. Na história João e Maria as crianças ajudaram a fantasiar o 
VI Congresso Brasileiro de Informática na Educação (CBIE 2017)

Anais do XXIII Workshop de Informática na Escola (WIE 2017)

RoPE como o personagem principal que tinha que achar o caminho de volta para casa e evitar encontrar a Bruxa. A Figura 6 ilustra o tapete que foi construído pela professora decidindo junto com as crianças os elementos e os caminhos a serem seguidos.

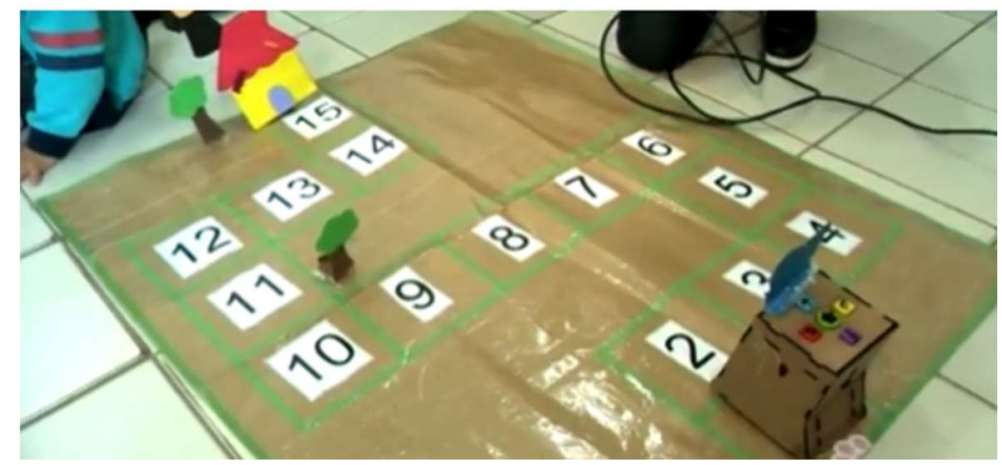

Figura 6 - Tapete associado a contação de histórias

A professora $B$ envolveu-se em uma atividade de construir um tapete em conjunto com as crianças. Ela Auxiliou a produzir as linhas retas e motivou as crianças a criarem um cenário para brincarem com o RoPE. A figura 7 ilustra o tapete criado pela professora em conjunto com as crianças, demonstrando as possibilidades de criação que o brinquedo proporciona, transcendendo os guias e materiais iniciais.

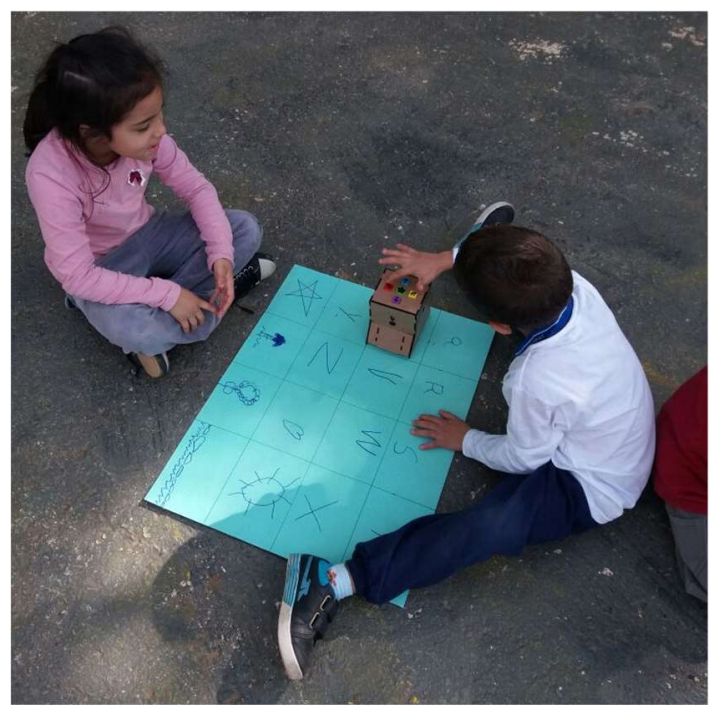

Figura 7 - Tapete criado com ajuda das crianças

Percebe-se também na figura 7 que as crianças realizaram a atividade no pátio da escola. Conhecer o brinquedo, desvendar suas possibilidades, pensar sobre quais ações serão possíveis com as crianças no ambiente educacional pode favorecer a novas descobertas, novos conhecimentos. Freire (2014) nos lembra o quanto "ensinar não é transferir conhecimento, mas criar as possibilidades para a sua produção ou a sua construção".

Foi gratificante para toda a equipe de pesquisadores que conceberam e construíram o RoPE saber que o modelo proposto do brinquedo de programar apresentado na escola avançou, passou a ser aceito e ressignificado pelas professoras reconstruindo 
outros materiais, formas diferentes de explorar o desenvolvimento das habilidades das sugeridas como modelo no manual.

O profissional de educação infantil quando proporciona a criança brincar com o brinquedo, a experimentar sensações diversas com o corpo, a expressar sentimentos e percepções, possivelmente despertará o encantamento pelas descobertas vivenciadas. É primordial na educação infantil o mediador proporcionar experiências e o contato com todas as linguagens o tempo todo. Pois cada criança tem uma forma diferente de aprender, dessa forma precisa saber como aprende, para que assim, possa mediar e orientar as crianças nas aprendizagens mais significativas que possam levá-las a aprender na realidade de seu cotidiano.

Entende-se que o brinquedo de programar RoPE tem contribuído de forma significativa neste processo, tornando-se muito mais do que um artefato para realização de tarefas pelas crianças, mas também como uma plataforma onde professores e crianças imaginam e concretizam cenários, histórias, desafios que possibilitam a expressão dos desejos, interesses, anseios e gostos das crianças e dos educadores.

\section{Considerações finais}

Os resultados apresentados são os primeiros relatos do uso sistemático de Brinquedos de Programar em escolas públicas no Brasil. O projeto RoPE deverá atender mais 10 núcleos de educação infantil até o final de 2017 atendendo a mais de 1600 crianças. $\mathrm{O}$ brinquedo foi concebido para colocar as crianças de educação infantil em contato com inovações tecnológicas, sem usar o computador, celular ou Tablet. Esta escolha se deu a percepção de que um brinquedo se integra facilmente a realidade do trabalho docente na educação infantil.

Elementos fundamentais do pensamento computacional como o pensamento algorítmico e a decomposição estão presentes em muitas das atividades realizadas com os brinquedos de programar. Discussões sobre a menor trajetória a ser realizada para atingir um local no tapete são realizadas naturalmente pelas crianças e trabalham uma noção concreta do conceito de otimização. Em uma situação uma criança decidiu otimizar seu prazer elaborando a estratégia mais longa possível para que pudesse brincar por mais tempo.

A intenção do projeto RoPE é levar estes conhecimentos de forma divertida não apenas para as crianças, mas também para os professores da educação infantil. As primeiras entregas dos brinquedos geraram pauta para diversos meios de comunicações regionais, como jornais, portais online e telejornais e uma publicação em jornal de circulação nacional de alto impacto. Fato que leva a crer que a sociedade anseia por possibilidades de inovar usando tecnologia para enriquecer a Educação das crianças.

\section{Aspectos Éticos}

Todas as crianças e professores retratados neste artigo autorizaram por escrito previamente o uso das imagens para fins de divulgação científica do projeto. 
VI Congresso Brasileiro de Informática na Educação (CBIE 2017)

Anais do XXIII Workshop de Informática na Escola (WIE 2017)

\section{Referências}

FREIRE, Paulo. Pedagogia da autonomia:saberes necessários à prática educativa. 49 ed., Rio de Janeiro:Paz e Terra, 2014.

HIGHFIELD, K. Mulligan, J. \& Hedberg, J. Early Mathematics Learning through Exploration with Programmable Toys. Proceedings of the Joint Meeting of PME 32 and PME-NA XXX. Vol 3. pp. 169 - 176. Mexico: International Group for the Psychology of Mathematics Education Psychology of Mathematics Education, 2008.

JANKA, P. Using a programmable toy at preschool age: why and how. Proceedings of SIMPAR, International Conference on Simulation, Modelling and Programming For Autonomous Robots, p. 112-121, Venice(Italy), 2008.

KAZAKOFF, E. R., \& Bers, M. U. (2013). The Wheels on the Bot go Round and Round: Robotics Curriculum in Pre-Kindergarten. Journal of Information Technology Education: Innovations in Practice, 12, 203-219.

MARTINS, Rodrigo Ramos. Desenvolvimento de uma metodologia para explorar habilidades de engenharia através do uso de brinquedos programáveis. Itajaí, 2016. $87 \mathrm{f}$. Trabalho Técnicocientífico de Conclusão de Curso (Graduação em Engenharia de Produção) - Centro de Ciências Tecnológicas da Terra e do Mar, Universidade do Vale do Itajaí, Itajaí, 2016.

PAPERT, S. A máquina das Crianças. Artmed. Porto Alegre, 2008.

PINHEIRO, Leonardo Antonio. Análise da Participação das Crianças em Atividades com Brinquedos Programáveis. Itajaí, 2016. 110 f. Trabalho Técnico-científico de Conclusão de Curso (Graduação em Ciência da Computação) - Centro de Ciências Tecnológicas da Terra e do Mar, Universidade do Vale do Itajaí, Itajaí, 2016.

RAABE, A. L. A; SANTANA, A. L. M; RODRIGUES, A. J; VIEIRA, M. V; ROSÁRIO, T; CARNEIRO, A. C. R. Brinquedos de Programar na Educação Infantil: Um estudo de Caso. Brinquedos de Programar na Educação Infantil: Um estudo de Caso. In: Anais do Workshop de Informática na Escola. 2015a. p. 42.

RAABE, André Luís Alice; VIEIRA, M. V. ; ROSARIO, Tatiane . Um relato de experiência com o uso do brinquedo de programar BEE-BOT na educação infantil com crianças de 3 e 4 anos. Revista Tecnologias na Educação, v. 13, p. 38-48, 2015 b.

RICHTER, D. R., SANTANA, A. L., RAABE, A. L., VIEIRA, M. F. V., \& RAMOS, R. Design de um Brinquedo Programável para Crianças de 4 a 5 anos de idade através da metodologia Design Thinking. Anais da Escola Regional de Informática da Sociedade Brasileira de Computação (SBC)-Regional de Mato Grosso, v. 1, n. 7, 2016.

SANTANA, André Luiz Maciel. Análise do Processo Metodológico de Montagem de um Brinquedo de Programar. 2015. Dissertação (Mestrado em Mestrado em Computação Aplicada) - Universidade do Vale do Itajaí, Orientador: André Luís Alice Raabe. 